\title{
Does arthroscopic repair show superiority over open repair of lateral ankle ligament for chronic lateral ankle instability: a systematic review and meta-analysis
}

Xiaosong Zhi ${ }^{1+} \mathbb{D}$, Zhuman $\mathrm{Lv}^{2+}$, Chen Zhang ${ }^{1+}$, Changwang Kong ${ }^{1}$, Shijun Wei ${ }^{1^{*}}$ and Feng $\mathrm{Xu}^{{ }^{1 *}}$

\begin{abstract}
Background: There is still no definite consensus on whether arthroscopic repair shows superiority over open repair for chronic lateral ankle instability. We conducted a systematic review and meta-analysis of the current comparative studies to make a generalized analysis.

Methods: PubMed, Embase, and Web of Science databases were searched from inception to April 2020. Included studies were assessed by the level of evidence and quality of evidence (Cochrane Handbook or MINORS). The process of data extraction was conducted by two independent authors. The comparative results of clinical outcomes, stress radiographic outcomes, and complication rates between two groups were pooled. Statistical analysis was performed using STATA.

Results: Nine comparative studies for a total of 473 patients (250 arthroscopic repair, 223 open repair) were included. For the clinical outcomes, a significant difference was found in favor of arthroscopic repair with regard to AOFAS scores (MD 0.32, 95\% Cl 0.12 to $0.53, P=7.7 \%, P=.370$ ) and VAS scores (MD $-0.30,95 \% \mathrm{Cl}-0.54$ to $0.05, P^{2}=48.3 \%, P=.102$ ). No significant difference was found regarding to stress radiographic outcomes. Importantly, the total complication rate (RR $0.88,95 \% \mathrm{Cl} 0.51$ to $1.49, P^{2}=0 \%, P=.957$ ) as well as nerve complication rate (RR $1.21,95 \% \mathrm{Cl} 0.53$ to $2.75, P^{2}=0 \%, P=.975$ ) of arthroscopic repair group is not significantly different to that of open repair group.

Conclusions: Arthroscopic repair for lateral ankle instability shows excellent clinical results comparable to open repair. Especially, arthroscopic repair might alleviate more pain due to the minimally invasive procedure. Patients receiving arthroscopic repair do not result in a higher total complication rate and nerve injury rate.
\end{abstract}

Keywords: Arthroscopic repair, Open repair, Lateral ankle ligament, Lateral ankle instability, Meta-analysis

\footnotetext{
*Correspondence: wsj1974@yeah.net; gkxf79390@sohu.com

'Xiaosong Zhi, Zhuman Lv and Chen Zhang contributed equally to this work.

'Department of Orthopaedics, General Hospital of Central Theater Command (Wuhan General Hospital of Guangzhou Command, previously), No. 627, Wuluo Road, Wuhan 430030, Hubei Province, PR China

Full list of author information is available at the end of the article
}

(c) The Author(s). 2020 Open Access This article is licensed under a Creative Commons Attribution 4.0 International License, which permits use, sharing, adaptation, distribution and reproduction in any medium or format, as long as you give appropriate credit to the original author(s) and the source, provide a link to the Creative Commons licence, and indicate if changes were made. The images or other third party material in this article are included in the article's Creative Commons licence, unless indicated otherwise in a credit line to the material. If material is not included in the article's Creative Commons licence and your intended use is not permitted by statutory regulation or exceeds the permitted use, you will need to obtain permission directly from the copyright holder. To view a copy of this licence, visit http://creativecommons.org/licenses/by/4.0/ The Creative Commons Public Domain Dedication waiver (http://creativecommons.org/publicdomain/zero/1.0/) applies to the data made available in this article, unless otherwise stated in a credit line to the data. 


\section{Background}

Ankle sprains are one of the most common injuries in activities/sports with a high recurrence rate, and repeated episodes could lead to chronic ankle instability, involving chronic insufficiency of the lateral ligament complex [1-3]. Among those, the anterior talofibular ligament (ATFL) is the most frequently affected ankle lateral ligamentfollowed by the calcaneofibular ligament (CFL) [4-7]. Conservative therapy is the initial treatment and is effective for major ankle sprains. However, there are still more than $20 \%$ of ankle sprains progressing into chronic lateral ankle instability and requiring operative treatments $[8,9]$.

The open modified Broström technique, first proposed in 1966, is an operative repair method for the lateral ankle ligaments when the ligament remnant is sufficient and the hindfoot alignment is good, and is widely regarded as the gold standard [10, 11]. This technique was modified by Gould in 1980 that reinforced the inferior extensor retinaculum (IER) after ATFL repair to strengthen ankle stability [12]. Recently, arthroscopic repair of the lateral ankle ligament, characterized by minimal invasiveness and fast recovery, has developed rapidly and has become increasingly popular [13, 14]. However, a high incidence of complications, especially postoperative nerve injury, is big trouble when arthroscopic repair is performed [15-18]. Up to date, there is inadequate clinical evidence in support of the use of arthroscopic repair or open repair techniques. In recent years, several clinical trials have aimed to compare arthroscopic and open repair for ATFL [11, 19-24]. These studies demonstrated some similar outcomes as well as different results between the two techniques after short- or mid-term follow-ups. However, there is still no definite consensus on which operative treatment shows overall or marked superiority over the other for chronic lateral ankle instability.

Our systematic review and meta-analysis aimed to comprehensively evaluate the current clinical evidence and statistically compare arthroscopic and open repair of lateral ankle ligament for chronic lateral ankle instability. We hypothesized that the current studies were in support of the arthroscopic repair technique concerning functional outcomes and complication rates when compared to the open repair technique.

\section{Materials and methods}

\section{Literature search strategy}

This study was conducted according to the guidelines outlined in the PRISMA (Preferred Reporting Items for Systematic Review and Meta-Analysis). PubMed, Embase, and Web of Science databases were searched to identify studies that reported the comparison between arthroscopic and traditional open procedures for chronic ankle instability up to April 2020. The search strategies were (Ankle instability OR Lateral ankle ligament OR talofibular) AND (Arthrosc* OR Endoscop*) AND (Minimally invasive OR open OR Broström). Additional studies were identified by secondary searches of reference lists of screened literature.

\section{Inclusion and exclusion criteria}

The studies included should meet the following criteria: (1) a randomized controlled trial (RCT), prospective cohort, or retrospective cohort study design; (2) reporting the comparison between arthroscopic and traditional open technique for chronic ankle instability (no language restriction); and (3) providing the follow-up (at least 12 months) data.

An article was excluded based on the following criteria: (1) review articles, meta-analysis, case reports, editorial, technique articles, cadaveric studies or animal experiments; (2) unable to provide sufficient data, e.g., abstract from a meeting/conference; and (3) duplicated studies.

\section{Quality assessment}

Each study was reviewed by two independent authors which graded the level of evidence [25]. Randomized studies were evaluated using the Cochrane Handbook (https://handbook-5-1.cochrane.org/). The risk of bias tool covers six items: selection bias, performance bias, detection bias, attrition bias, reporting bias, and other bias. Each item was categorized as "high," "low," or "unclear." Non-randomized studies were assessed by methodological index for non-randomized studies (MINORS) containing 12 items with a global ideal score of 24 for comparative studies [26]. Any discrepancy was resolved by consulting an expert investigator until a consensus was reached.

\section{Data extraction}

The data was extracted by two independent authors (Zhi $\mathrm{X}$ and Zhang $\mathrm{C}$ ) based on inclusion and exclusion criteria mentioned above. The following information was collected: the last name of the first author, publication year, level of evidence, study design, publication country, number of patients, mean age, operative technique, follow-up time, operative time, clinical outcome, radiographic outcome, complication rate, and revision rate. Any disagreement was resolved by rechecking until a consensus was reached.

\section{Statistical analysis}

Counting variables were analyzed with event number and total number. Continuous variables were analyzed with the weighted mean difference (MD). When a standard deviation of continuous variables was not reported, 
we contacted the corresponding author or calculated it through a method reported by Hozo et al. using the available data if possible [27]. Heterogeneity among studies was quantified using the $I^{2}$ statistic [28]. $I^{2}>50 \%$ was considered to indicate substantial heterogeneity. When the $I^{2}$ value was greater than 50\%, the random effect model was applied. When $I^{2}$ was less than $50 \%$, the fixed effect model was used. STATA version 12.0 (StataCorp LP, College Station, TX, USA) was used for the whole meta-analysis. Statistical significance was set at $P<.05$.

\section{Results}

\section{Literature search}

The electronic database search and additional search finally yielded 701 results after duplicate records were removed. The studies were screened by reviewing abstracts and full-text according to the inclusion and exclusion criteria, and nine studies were eligible for the final meta-analysis, including one randomized controlled trial (RCT), one prospective cohort study, and seven retrospective cohort studies. The studies were published from 2016 to 2020. Of those, one study was conducted in Republic of Korea, one in Japan, two in the USA, one in Singapore, and four in China. The detailed information is shown in Fig. 1 and Table 1. This study followed the PRISMA 2009 checklist as provided in Additional file 1.

\section{Patient demographics}

Four hundred seventy-three ankles were repaired in these 7 studies, of those, 250 with arthroscopic repair and 223 ankles with open procedures. The operations of all cases were performed in the time range of 20092019. All patients from the included studies received traditional open or arthroscopic Broström-Gould operations, with one or two suture anchors. The weighted mean age (years) of patients are 37.3 for the arthroscopic group and 33.3 for the open group. The overall weighted mean follow-up was 25.9 months (range 12-44.4 months). The weighted mean follow-up for cases with arthroscopic repair was 23.8 months (range 12-39.7 months), and that for cases with open procedures was 28.2 months (range 12-44.4 months). All patient demographics are summarized in Table 1.

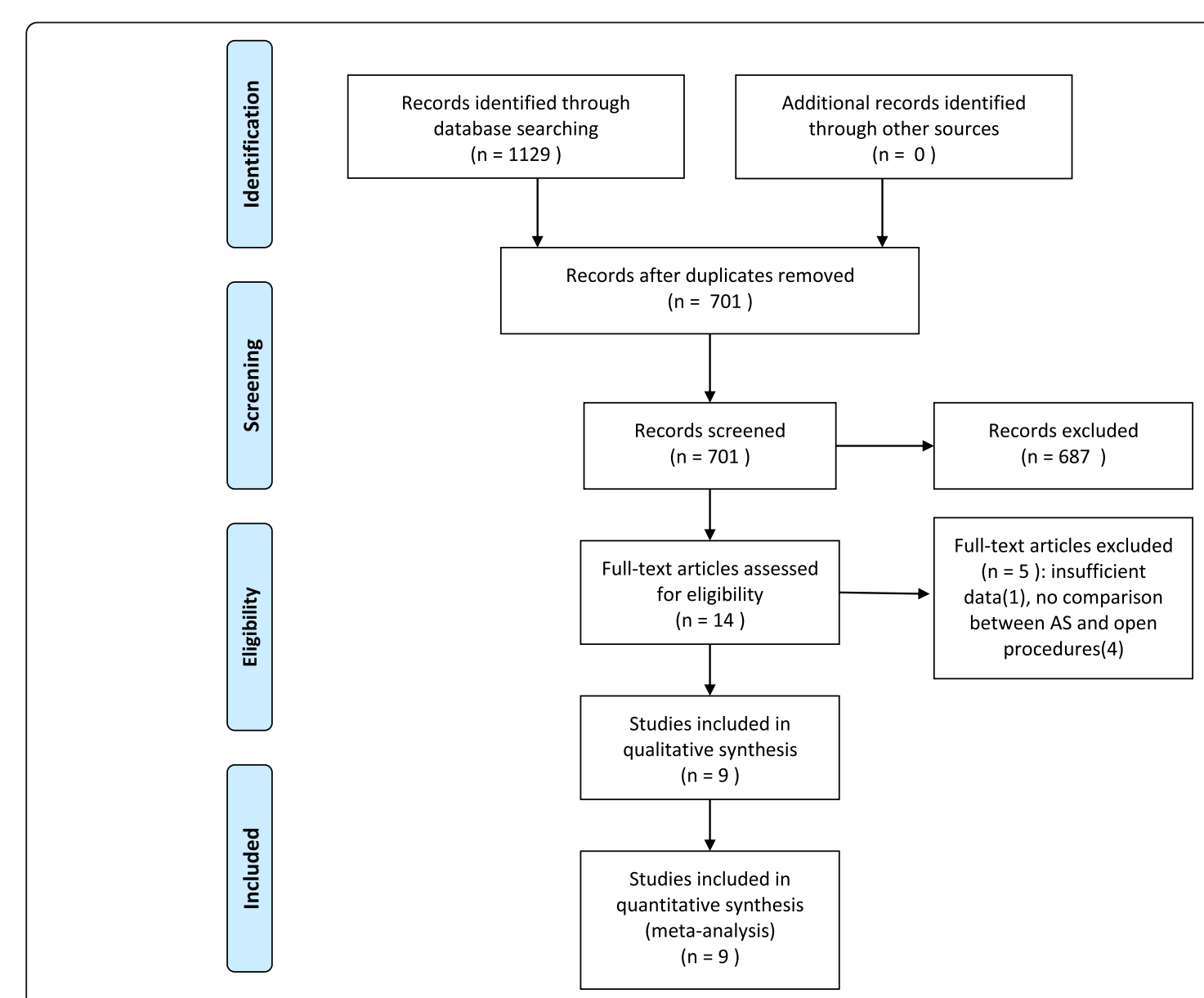

Fig. 1 Flowchart of the literature selection 
Table 1 Characteristics of included studies

\begin{tabular}{|c|c|c|c|c|c|c|c|c|c|c|}
\hline \multirow{2}{*}{$\begin{array}{l}\text { Study } \\
\text { Yeo et al. }\end{array}$} & \multirow{2}{*}{$\begin{array}{l}\text { Year } \\
2016\end{array}$} & \multirow{2}{*}{$\begin{array}{l}\text { LOE } \\
1\end{array}$} & \multirow{2}{*}{$\begin{array}{l}\text { Type of study } \\
\text { RCT }\end{array}$} & \multirow{2}{*}{$\begin{array}{l}\text { Country } \\
\text { Republic } \\
\text { of Korea }\end{array}$} & \multicolumn{2}{|c|}{$\begin{array}{l}\text { No. of } \\
\text { patients }\end{array}$} & \multirow{2}{*}{$\begin{array}{l}\text { Age(years) } \\
35.2\end{array}$} & \multirow{2}{*}{$\begin{array}{l}\text { Operative technique } \\
\text { AS-assisted Broström-Gould, } \\
1 \text { suture anchors }\end{array}$} & \multirow{2}{*}{$\begin{array}{l}\text { Follow-up } \\
\text { (months) } \\
12\end{array}$} & \multirow{2}{*}{$\begin{array}{l}\text { Operative } \\
\text { time } \\
2012-2014\end{array}$} \\
\hline & & & & & 48 & AS 25 & & & & \\
\hline & & & & & & Open 23 & 34.3 & $\begin{array}{l}\text { Broström-Gould, } 1 \text { suture } \\
\text { anchors }\end{array}$ & 12 & \\
\hline \multirow[t]{2}{*}{ Matsui et al. } & 2016 & 3 & $\begin{array}{l}\text { Retrospective } \\
\text { cohort }\end{array}$ & Japan & 37 & AS 19 & 28 & $\begin{array}{l}\text { All-inside Broström-Gould, } \\
2 \text { suture anchors }\end{array}$ & 12 & 2013-2014 \\
\hline & & & & & & Open 18 & 24 & $\begin{array}{l}\text { Broström-Gould, } 2 \text { suture } \\
\text { anchors }\end{array}$ & 12 & \\
\hline \multirow[t]{2}{*}{ Li et al. } & 2017 & 3 & $\begin{array}{l}\text { Prospective } \\
\text { cohort }\end{array}$ & China & 60 & AS 23 & 30.3 & $\begin{array}{l}\text { All-inside Broström-Gould, } \\
1 / 2 \text { suture anchors }\end{array}$ & 39.7 & 2012-2014 \\
\hline & & & & & & Open 37 & 28.7 & $\begin{array}{l}\text { Broström-Gould, } 1 / 2 \text { suture } \\
\text { anchors }\end{array}$ & 35.5 & \\
\hline \multirow[t]{2}{*}{ Rigby et al. } & 2018 & 3 & $\begin{array}{l}\text { Retrospective } \\
\text { cohort }\end{array}$ & USA & 62 & AS 30 & 47.9 & $\begin{array}{l}\text { AS-assisted Broström-Gould, } \\
2 \text { suture anchors }\end{array}$ & 15.6 & 2009-2013 \\
\hline & & & & & & Open 32 & 37.7 & $\begin{array}{l}\text { Broström-Gould, } 2 \text { suture } \\
\text { anchors }\end{array}$ & 44.4 & \\
\hline \multirow[t]{2}{*}{ DeVries et al. } & 2019 & 3 & $\begin{array}{l}\text { Retrospective } \\
\text { cohort }\end{array}$ & USA & 55 & AS 43 & 44.7 & $\begin{array}{l}\text { All-AS Broström-Gould, } \\
2 \text { suture anchors }\end{array}$ & 24.2 & 2014-2016 \\
\hline & & & & & & Open 12 & 39.5 & $\begin{array}{l}\text { Broström-Gould, } 2 \text { suture } \\
\text { anchors }\end{array}$ & 21 & \\
\hline \multirow[t]{2}{*}{ Yi et al. } & 2019 & 3 & $\begin{array}{l}\text { Retrospective } \\
\text { cohort }\end{array}$ & China & 65 & AS 35 & 39.3 & $\begin{array}{l}\text { All-inside Broström-Gould, } \\
1 \text { suture anchors }\end{array}$ & 26 & 2014-2017 \\
\hline & & & & & & Open 30 & 37.3 & $\begin{array}{l}\text { Broström-Gould, } 1 \text { suture } \\
\text { anchors }\end{array}$ & 26 & \\
\hline \multirow[t]{2}{*}{ Zeng et al. } & 2020 & 3 & $\begin{array}{l}\text { Retrospective } \\
\text { cohort }\end{array}$ & China & 27 & AS 17 & 30.9 & $\begin{array}{l}\text { All-AS Broström-Gould, } \\
1 \text { suture anchors }\end{array}$ & 36 & 2013-2015 \\
\hline & & & & & & Open 10 & 27.7 & $\begin{array}{l}\text { Broström-Gould, } 1 \text { suture } \\
\text { anchors }\end{array}$ & 36 & \\
\hline \multirow[t]{2}{*}{ Xu et al. } & 2020 & 3 & $\begin{array}{l}\text { Retrospective } \\
\text { cohort }\end{array}$ & China & 67 & AS 32 & 33.7 & $\begin{array}{l}\text { Arthroscopic-assisted Broström, } \\
1 / 2 \text { suture anchors }\end{array}$ & 36.5 & 2015-2017 \\
\hline & & & & & & Open 35 & 35.8 & $\begin{array}{l}\text { Broström-Gould, } 1 / 2 \text { suture } \\
\text { anchors }\end{array}$ & 39.1 & \\
\hline \multirow[t]{2}{*}{ Woo et al. } & 2020 & 3 & $\begin{array}{l}\text { Retrospective } \\
\text { cohort }\end{array}$ & Singapore & 52 & AS 26 & 33.4 & $\begin{array}{l}\text { All-AS Broström-Gould, } \\
2 \text { suture anchors }\end{array}$ & 12 & 2015-2019 \\
\hline & & & & & & Open 26 & 31.5 & $\begin{array}{l}\text { Broström-Gould, } 1 \text { suture } \\
\text { anchors }\end{array}$ & 12 & \\
\hline
\end{tabular}

Abbreviations: $L O E$ level of evidence, $R C T$ randomized controlled trial, $A S$ arthroscopic

\section{Quality assessment}

According to established criteria, there was one study of LOE I and eight studies of LOE III. The study of Yeo et al. [11] was a RCT, so it was assessed by the Cochrane Handbook. The bias was assessed as selection bias (low), performance bias (low), detection bias (unclear, for inadequate information for the patients lost to follow-up), attrition bias (low), reporting bias (low), and other biases (low). The other studies were comparative non-randomized studies and were assessed by MINORS. All of the 8 non-randomized studies were scored above 17: Matsui et al. (17) [19], Li et al. (20) [20], Rigby et al. (18) [21], DeVries et al. (20) [22], Yi et al. (20) [23], Zeng et al. (18) [24], Xu et al. (22) [29], Woo et al. (19) [30].

\section{Clinical outcome}

The American Orthopaedic Foot \& Ankle Society (AOFAS) score was given in 7 studies with 188 patients treated with the arthroscopic repair and 193 patients treated with the open repair. In the final follow-up evaluation, the average AOFAS score with the arthroscopic repair was 92.3, and the average AOFAS score with the open repair was 90.8. There was a statistically significant difference in favor of the arthroscopic repair (MD 0.32, 95\% CI 0.12 to $0.53, I^{2}=7.7 \%, P=.370$ ) (Fig. 2). For short-term outcome, Yi et al. reported that AOFAS score at 2 weeks after operation in the arthroscopic group was $79.5 \pm 6.4$, significantly higher than that score in the open group that was $76.3 \pm 4.9$ $(t=2.234, P=.029)[23]$. 


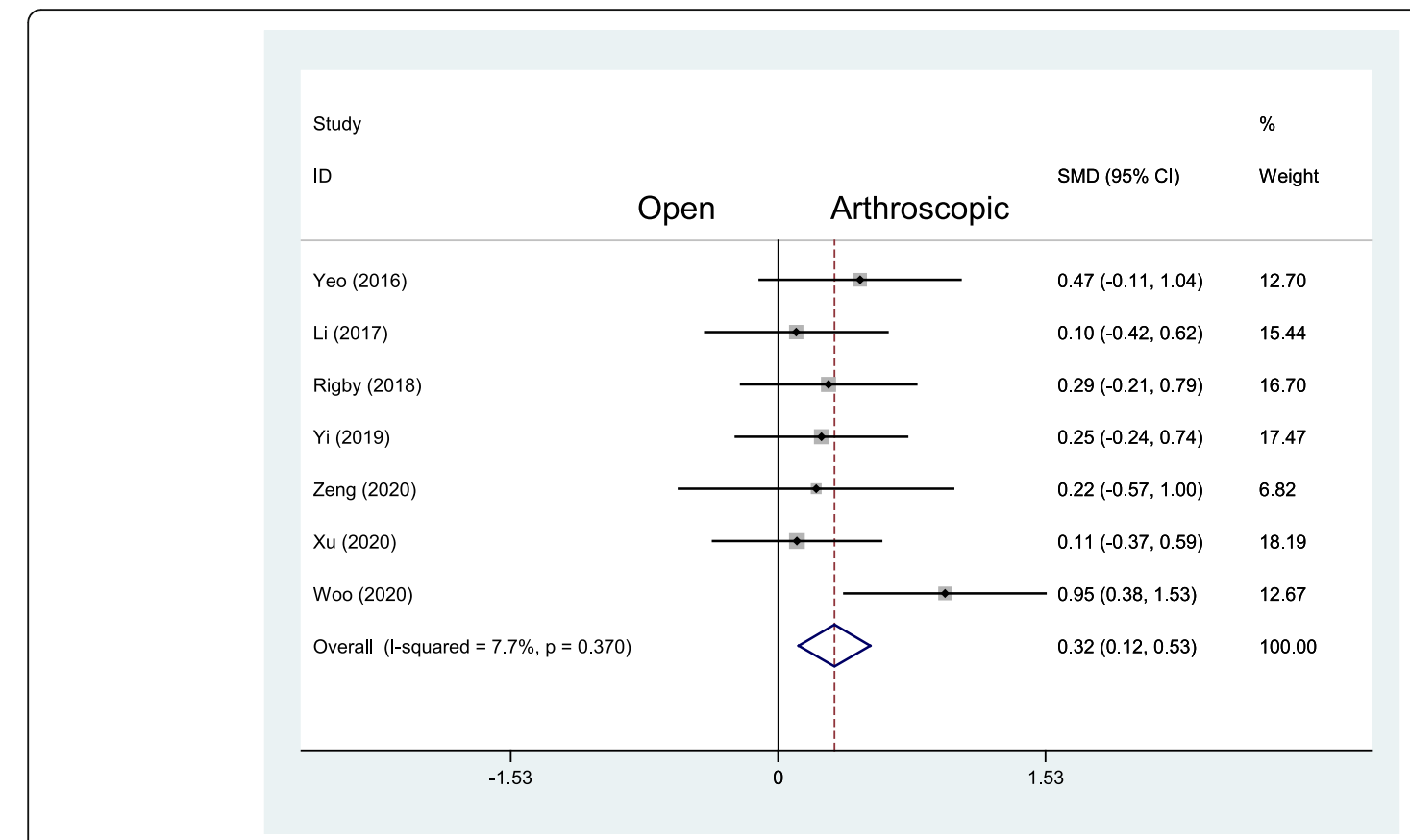

Fig. 2 Forest plots of the comparison of arthroscopic and open technique for AOFAS score

The Karlsson score was reported in 6 studies with 162 patients treated with the arthroscopic repair and 167 patients with the open repair. In the final followup evaluation, the average Karlsson score with the arthroscopic repair was 86.6, and with the open repair the mean value was 86.3 . There was no statistically significant difference (MD 0.13, 95\% CI -0.09 to
0.35, $I^{2}=49.5 \%, P=.078$ ) (Fig. 3). But for the shortterm results from Yi et al., Karlsson score at 2 weeks after operation in the arthroscopic group was $77.2 \pm$ 8.8, significantly higher than in the open group that was $73.4 \pm 5.8(t=2.065, P=.043)$ [23].

The visual analog scale (VAS) score for pain evaluation was reported in 5 studies with 132 patients treated with

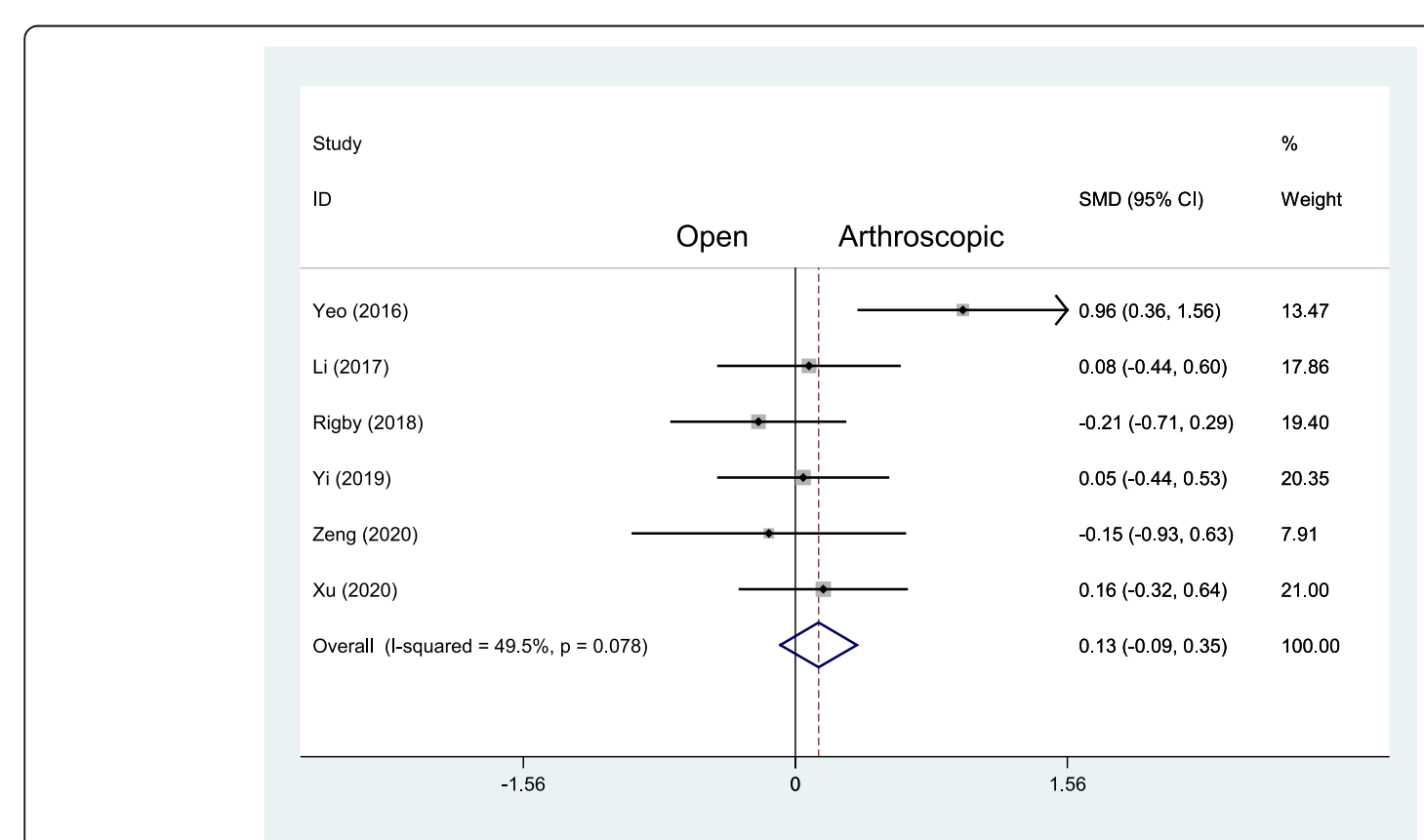

Fig. 3 Forest plots of the comparison of arthroscopic and open technique for Karlsson score 
the arthroscopic repair and 134 patients treated with the open repair. In the final follow-up evaluation, the average VAS score with the arthroscopic repair was 1.51, significantly lower than 1.84 in the open repair group $\left(\mathrm{MD}-0.30,95 \% \mathrm{CI}-0.54\right.$ to $-0.05, I^{2}=48.3 \%, P=$ .102) (Fig. 4). According to the studies of Yeo et al. [11] and Matsui et al. [19], the VAS score of both groups were not significantly different at short-term follow-ups ( 2 weeks and 6 weeks).

Two studies $[19,23]$ reported with the Japanese Society for Surgery of the foot ankle-hindfoot (JSSF) scale score with 54 patients being treated with the arthroscopic repair and 48 patients being treated with the open repair. Yi et al. [23] reported that JSSF score at 2 weeks after operation in arthroscopic group was $87.8 \pm 8.4$ and that in the open group was $83.5 \pm 7.6$ with significant difference $(t=2.149, P=.035)$. Whereas, there was no statistically significant difference when JSSF score was assessed at 3 months [23], and at the final follow-ups $[19,23]$ after operation.

\section{Stress radiographic outcome}

In the pooled results from Yeo et al., Yi et al., and Zeng et al., no significant difference were found in postoperative anterior displacement (MD $-0.14,95 \% \mathrm{CI}-0.47$ to $0.20, I^{2}=0.0 \%, P=.891$ ) (Fig. $5 \mathrm{a}$ ) or tilt angle of the talus between the two groups (MD 0.23, 95\% CI -0.11 to $0.56, I^{2}=0.0 \%, P=.771$ ) (Fig. $5 \mathrm{~b}$ ). In the studies of Yeo et al. [11] and Zeng et al. [24], stress radiographic data revealed no significant difference of change (preoperative to postoperative) of either anterior displacement or tilt angle of the talus between the two groups. In the studies of Matsui et al. [19] and Yi et al. [23], no significant difference existed in preoperative or postoperative anterior displacement of the talus between the two groups. Additionally, there was also no significant difference when comparing the tilt angle of the talus between the two groups [23]. The remaining studies did not report the data of the stress radiographic outcomes.

\section{Complications and revisions}

The complications were reported in 9 studies with 250 patients treated with the arthroscopic repair, including 12 had nerve injuries, 5 had knot pain, 1 had persistent pain, 1 had deep venous thrombosis (DVT), 1 had an infection, 1 suffered from poor healing, and 5 had revisions (Table 2). In 223 patients treated with the open repair, there were 9 nerve injuries, 4 infections, 3 wound irritations, 2 had persistent pain, 1 had tendinitis, 3 had knot pain, and 2 suffered from poor healing (Table 2). None of the patients were reported to receive a revision surgery in the open group (Table 2). Arthroscopic cases had a total complication rate of $10.4 \%$, whereas the total complication rate of the open repair was $10.8 \%$. There was no statistically significant difference between the two techniques with regard to the overall complication rate (RR $0.88,95 \%$ CI 0.51 to $1.49, I^{2}=0 \%, P=.957$ ) (Fig. 6a). Then we compared the nerve complication rate between the two groups additionally. The results showed that no statistically significant difference existed between the two techniques concerning the nerve complication rate (RR 1.21, 95\% CI 0.53 to 2.75, $I^{2}=0 \%, P=.975$ ) (Fig. 6b).

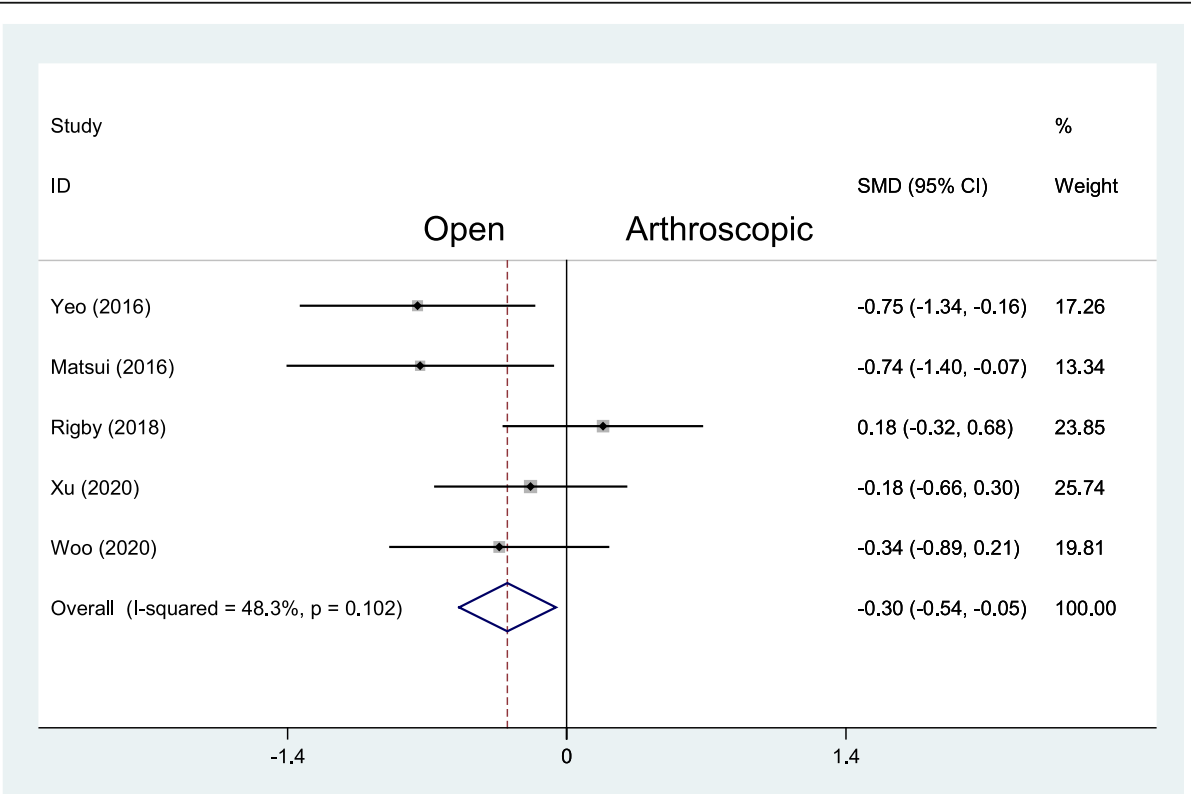

Fig. 4 Forest plots of the comparison of arthroscopic and open technique for VAS score 

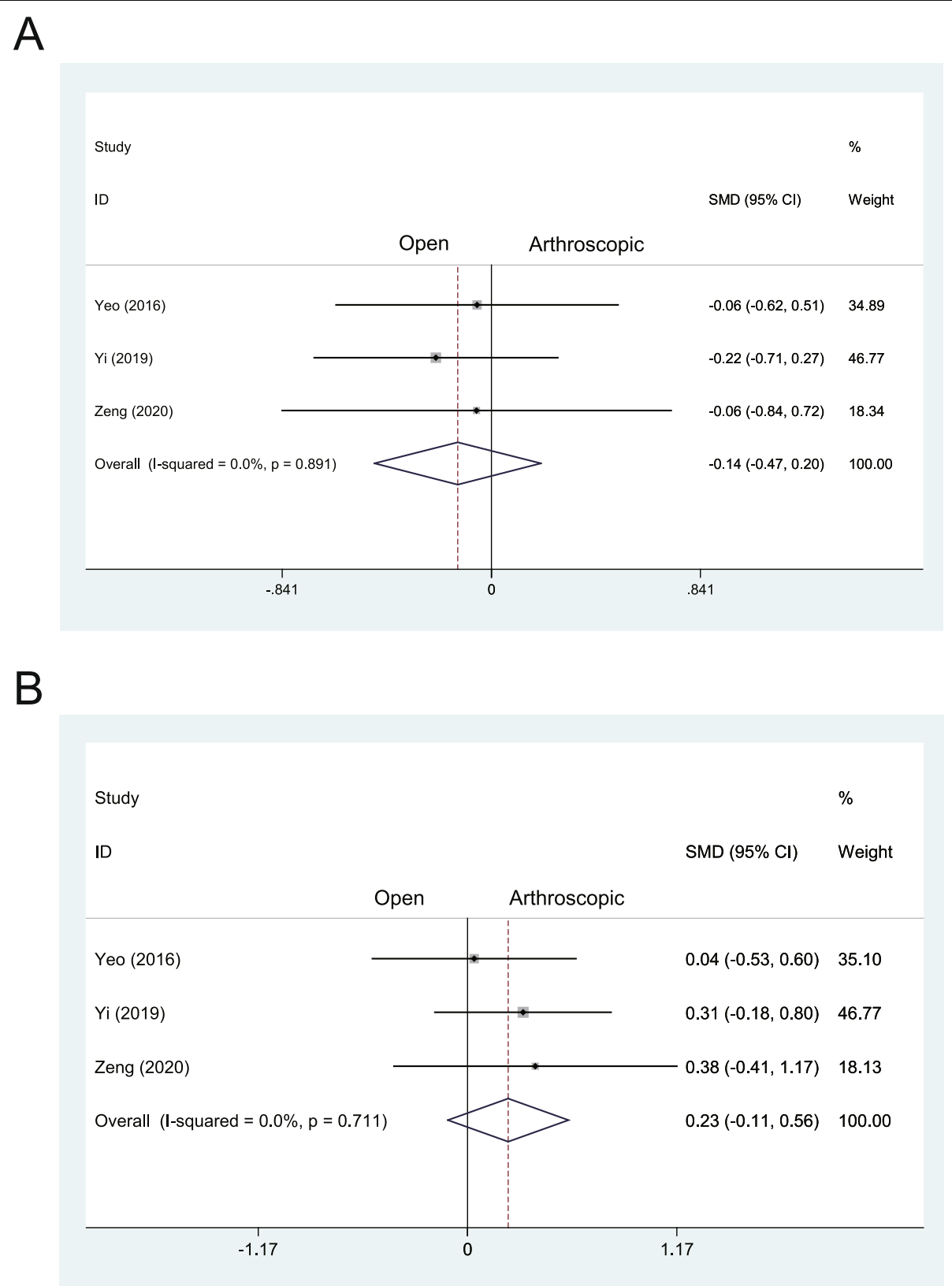

Fig. 5 a Forest plots of the comparison of arthroscopic and open technique for anterior displacement of talus at final follow-up. $\mathbf{b}$ Forest plots of the comparison of arthroscopic and open technique for tilt angle of talus at final follow-up

\section{Return to full activity/sports}

Matsui et al. [19] reported that the mean time to return to daily activity was significantly shorter in the arthroscopic group: 5.3 (range 3-12) weeks vs 7.1 (range 5-12) weeks in the open group $(P<.05)$. However, there was no significant difference in mean time to return to activity/sports: 16.5 (range 12-22) weeks in the arthroscopic group vs 17.1 (range 13-22) weeks in the open group ( $P$ $=.07)$. Yi et al. [23] reported that the length of time to recover from surgery was $5.4 \pm 1.7$ weeks in the arthroscopic group, and that time was $7.2 \pm 2.3$ weeks in the open group, with significant difference $(t=3.620, P=$ $.001)$. Rigby et al. [21] reported that the rate of return to sports activity was $96.7 \%$ (29 of 30 patients) in the arthroscopic group and $96.9 \%$ (31 of 32 patients) in the open group. DeVries et al. [22] showed that the 35 out of 43 patients returned to activity/sports in the arthroscopic group, the returning time was $127.2 \pm 96.3$ (range 53-569) days. Nine out of 12 patients returned to activity/sports in the open group, the returning time was $170.7 \pm 66.4$ (range 56-174) days. There was a statistically significant difference between the groups with 
Table 2 Outcomes and complications in identified studies

\begin{tabular}{|c|c|c|c|c|c|c|c|c|c|}
\hline Study & Group & AOFAS & Karlsson & VAS & JSSF & $\begin{array}{l}\text { Anterior drawer } \\
\text { test } \\
(\mathrm{mm})\end{array}$ & $\begin{array}{l}\text { Talar tilt angle } \\
\left({ }^{\circ}\right)\end{array}$ & Complication rate & Revision rate \\
\hline \multirow[t]{2}{*}{ Yeo et al. } & AS & 90.3 & 76.2 & 1.7 & NR & $-1.7(8.4$ to 6.7$)$ & $-3.4(7.3$ to 3.9$)$ & 20\%(3:nerve injury, 2:knot pain) & NR \\
\hline & open & 89.2 & 73.5 & 2 & NR & $-1(7.8$ to 6.8$)$ & $-1.6(5.4$ to 3.8$)$ & 13\%(2:nerve injury, 1:infection) & NR \\
\hline \multirow[t]{2}{*}{ Matsui et al. } & AS & NR & NR & 1.2 & 98 & $-5.6(8.4$ to 2.8$)$ & $-6.8(10$ to 3.2$)$ & $10.5 \%(2:$ nerve injury) & $0 \%$ \\
\hline & open & NR & NR & 1.9 & 95.4 & $-6.2(9.1$ to 2.9$)$ & $-7(9.9$ to 2.9$)$ & $\begin{array}{l}22.2 \%(3: \text { wound irritation, } \\
\text { 1:nerve injury) }\end{array}$ & $0 \%$ \\
\hline \multirow[t]{2}{*}{ Li et al. } & AS & 93.3 & 90.3 & NR & NR & NR & NR & 4.3\%(1:persistent pain) & $0 \%$ \\
\hline & open & 92.4 & 89.4 & NR & NR & NR & NR & 5.4\%(2:persistent pain) & $0 \%$ \\
\hline \multirow[t]{2}{*}{ Rigby et al. } & AS & 95.33 & 91.8 & 1.5 & NR & NR & NR & 6.7\%(1:nerve injury, 1:DVT) & NR \\
\hline & open & 93.53 & 93.41 & 1.2 & NR & NR & NR & 6.3\%(2:nerve injury) & NR \\
\hline \multirow[t]{2}{*}{ DeVries et al. } & AS & NR & NR & NR & NR & NR & NR & 14\%(5:revision, 1:infection) & $11.6 \%$ \\
\hline & open & NR & NR & NR & NR & NR & NR & 16.7\%(1:tendinitis, 1:infection) & $0 \%$ \\
\hline \multirow[t]{2}{*}{ Yi et al. } & AS & 93.4 & 89.3 & NR & 97.2 & $-5.4(8.6$ to 3.2$)$ & $-5.5(8.8$ to 3.3$)$ & 8.6\%(2:nerve injury, 1:knot pain) & $0 \%$ \\
\hline & open & 91.8 & 88.9 & NR & 95.6 & $-5.6(8.9$ to 3.3$)$ & $-6.4(9.5$ to 3.1$)$ & 13.3\%(2:nerve injury, 2:knot pain) & $0 \%$ \\
\hline \multirow[t]{2}{*}{ Zeng et al. } & AS & 92.4 & 89.2 & NR & NR & $-2.8(12.9$ to 10.1$)$ & $-2.4(11.2$ to 8.8$)$ & 11.8\%(1:nerve injury, 1:poor healing) & NR \\
\hline & open & 91.1 & 90.5 & $N R$ & NR & $-3.3(13.6$ to 10.3$)$ & $-2.7(10.4$ to 7.7$)$ & 30\%(1:knot pain, 2:poor healing) & $N R$ \\
\hline \multirow[t]{2}{*}{ Xu et al. } & AS & 87.7 & NR & 1.8 & NR & NR & NR & 15.6\%(3:nerve injury, 2:knot pain) & NR \\
\hline & open & 86.9 & NR & 2.1 & NR & NR & NR & 11.4\%(2:nerve injury, 2:infection) & NR \\
\hline \multirow[t]{2}{*}{ Woo et al. } & AS & 94.2 & NR & 1.2 & NR & NR & NR & $0.0 \%$ & $0 \%$ \\
\hline & open & 70.9 & NR & 2.1 & NR & NR & NR & $0.0 \%$ & $0 \%$ \\
\hline
\end{tabular}

Abbreviations: AOFAS American Orthopaedic Foot and Ankle Society, VAS visual analog scale; JSSF Japanese Society for Surgery of the foot ankle-hindfoot, AS arthroscopic, NR not reported, DVT deep venous thrombosis

regard to the time other than the rate to return to activity/sports $(P=.008)$. The remaining studies did not report time of surgery recovery and returning to activity/ sports.

\section{Discussion}

The highlight of this study was that arthroscopic repair of ATFL is a very safe and alternative technique for restoring lateral ankle instability. The comprehensive results suggest that arthroscopic repair of ATFL may result in superior clinical outcomes (AOFAS and VAS score) over open ATFL repair, although no significant difference is found for the stress radiographic outcomes between the two techniques. Additionally, the total complication rate and nerve complication rate were shown to be similar between the two procedures.

The surgical treatment for ATFL injury includes ATFL repair and ATFL reconstructive technique (preservation of ATFL or no preservation of ATFL) [31]. The open Broström-Gould procedure is widely accepted as the gold standard technique for lateral ankle ligament repair [32]. The technique is one method of anatomical repair of the ATFL with many advantages, e.g., low technical complexity, low incidence of complications, allowing subtalar motion and showing good clinical effectiveness $[10,33]$. Arthroscopic ankle stabilization was first described by Hawkins [13] by using a staple technique and developed by Ferkel and Scranton [34] in the 1990s. But arthroscopic repair did not gain popularity in that time due to higher complexity, longer operative time, and more complications compared to conventional open repair [18, 24]. Kashuk et al. firstly performed an arthroscopic technique using suture anchors for lateral ligamentous complex repair, which offered the benefit of quicker recovery [35]. With the rapid development of arthroscopic instruments and the simplification of arthroscopic repair techniques, the advantages of minimally invasive arthroscopy have become more apparent [24]. Besides, other intraarticular lesions can be simultaneously treated during arthroscopic procedures [36]. However, the complication rate remains relatively high [37]. Recent nine studies respectively aimed to find the evidence-based advantages of either technique by comparing the arthroscopic repair and conventional open procedure in clinical trials. However, individual studies show a low level of evidence, so there is still no clear consensus on which operative treatment possesses superiority over the other for chronic lateral ankle instability. Thus, we performed this meta-analysis of the nine comparative studies to achieve a comprehensive evaluation. 


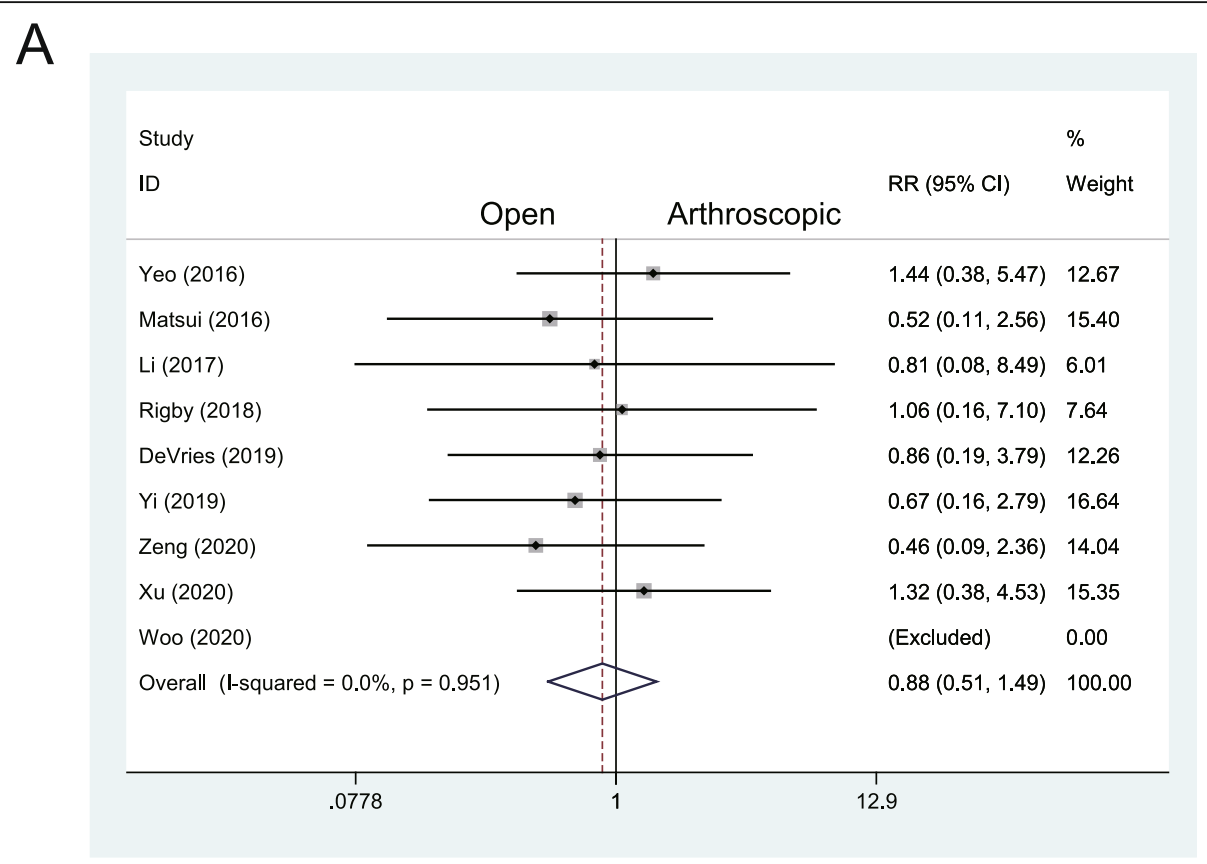

B

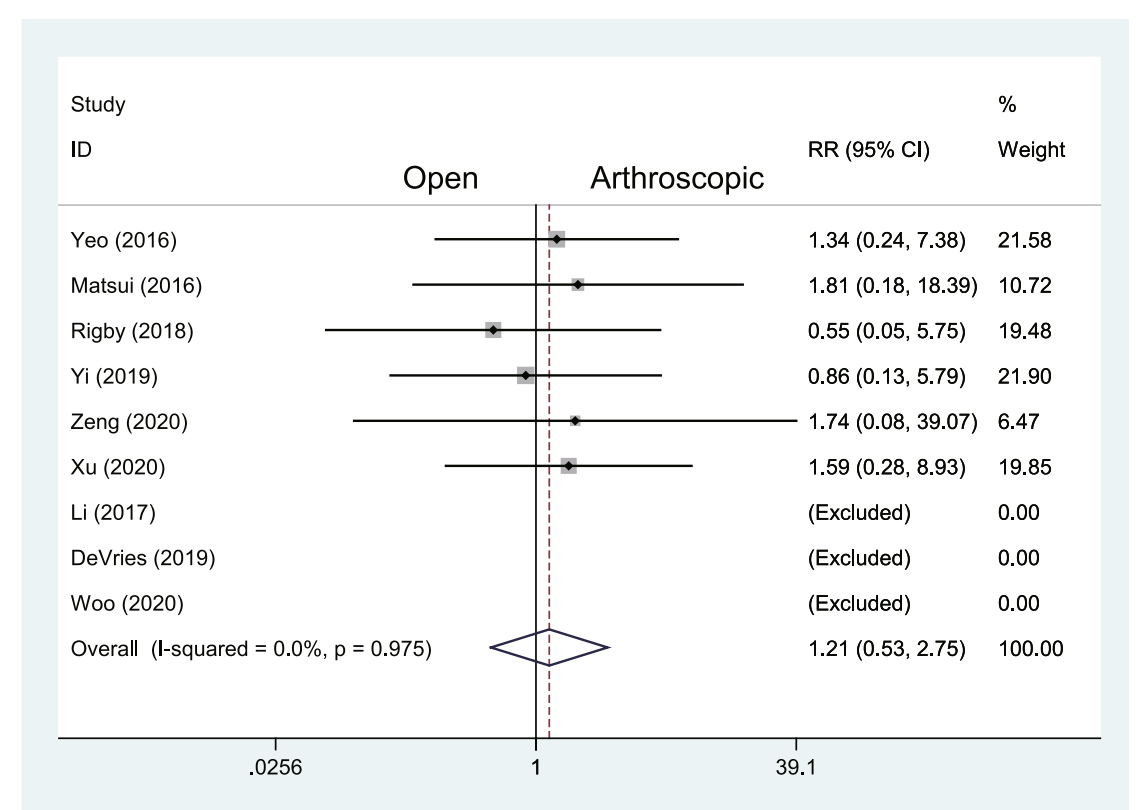

Fig. $\mathbf{6}$ a Forest plots of the comparison of arthroscopic and open technique for total complication rate. $\mathbf{b}$ Forest plots of the comparison of arthroscopic and open technique for nerve complication rate

We found that the arthroscopic repair showed an overall better AOFAS score than the open method in final follow-ups. However, there is no significant difference between the two groups when comparing the Karlsson-Peterson scores in final follow-ups. These results were similar to the previous meta-analysis by Brown et al. [38]. Interestingly, we also compared the VAS scale between the two groups, and from the pooled results, we found that arthroscopic repair might alleviate more pain due to the minimally invasiveness of this procedure. When it comes to early recovery, AOFAS scores, Karlsson scores, and JSSF scores at 2 weeks after surgery seem to be in support of arthroscopic repair [23]. However, Yeo et al. reported that there was no significant difference between the two groups when AOFAS scores, Karlsson scores, and VAS scores were evaluated at 6 weeks after surgery [11]. Actually, in our clinical work, we found that the AOFAS score was not the best 
evaluation scale for ankle instability and the Karlsson score was more effective.

With regard to the stress radiographic outcomes, the talar tilt angle and anterior displacement of the talus are the most common index for evaluation. From the included studies, no matter for the preoperative comparison, postoperative comparison, or for the change (preoperative to postoperative) of the talar tilt angle and anterior displacement of the talus, radiographic outcomes did not show significant difference between the arthroscopic group and the open group. However, whether stress radiographs is indispensable for diagnosis or assessing clinical outcomes remains debatable [39, 40]. Lee et al. [41] explained that the results of the stress radiographs were not so reliable because of the possibility of false-negative errors in case of muscle contraction. Furthermore, Hertel et al. [42] reported that patients with functional ankle instability showed normal stress radiographic outcomes. MRI is a valuable diagnosing method for evaluating intra-articular pathology, but it is more used to find abnormality of the lateral ankle ligament as well as concomitant injury rather than to evaluate the clinical outcomes after surgery [43].

Although a previous systematic review reported that the arthroscopic technique had a complication rate of $15.27 \%$, higher than that of $7.92 \%$ in the open repair [18], from the pooled results of our study, there was no statistically significant difference between the two groups (10.4\% for the arthroscopic repair, $10.8 \%$ for the open repair). One of the most common complications is the occurrence of nerve injury, especially during arthroscopic repair procedures [44]. The arthroscopic techniques include arthroscopic-assisted techniques, allarthroscopic techniques, and all-inside techniques [45]. Among those, suture knots of all-inside techniques are tied within the joint, while sutures are tied extracapsularly in the other two techniques, which increase the risk of entrapment of surrounding anatomical structures and increase the complicate rate [46]. In order to reduce the incidence of nerve injury during arthroscopic repair, Acevedo et al. identified a "safe zone," with a mean length of $51 \mathrm{~mm}$ between the intermediate branch of the superficial peroneal nerve (SPN) and sural nerve, and found that a safe distance of $20 \mathrm{~mm}$ (range, $8-36 \mathrm{~mm}$ ) was maintained from the most medial suture to the intermediate branch of the SPN [47]. With the simplification of arthroscopic technique and repeated training of surgeons, the incidence of nerve injuries is becoming much lower now than before $[19,20,47,48]$. In this meta-analysis, the complication rate of nerve injuries is $4.69 \%$ in the arthroscopic repair, and $4.32 \%$ in the open group, also with no statistically significant difference.

A systematic review reported by So et al. included 11 studies involving 669 cases receiving the open Broström-
Gould procedures, and the revision rate was $1.2 \%$ at a weighted mean follow-up of 8.4 years [49]. A prospective study by Lopes et al. of 286 patients with the arthroscopic repair or reconstruction reported a $4.2 \%$ revision rate during mean follow-up of 9.6 months [50]. Up to date, there are rare studies comparing revision rate between the two techniques. In this review, 5 of the 9 studies reported a $0 \%$ revision rate in the open repair, and the other 4 studies did not report this data. For the arthroscopic repair, 4 of the 9 studies reported a $0 \%$ revision rate, whereas, one study reported an $11.6 \%$ revision rate, much higher than the other studies. So, the current evidence for revision of arthroscopic repair is still limited and further studies with larger amounts of patients are necessary.

Returning to activity/sports indicated a mid- to longterm recovery from ankle instability. In this review, Rigby et al. [21] found that the rates of returning to sports in the two groups were both $97 \%$, and Matsui et al. [19] stated that no significant difference existed between the two groups with regard to the mean time of returning to sports. Only DeVries et al. [22] found that the returning time to activity/sports in the arthroscopic group was shorter than that in the open group, but the returning rate showed no significant difference. It is noteworthy that faster recovery and earlier return to activity/sports may rely not only on operative techniques but also on postoperative management. A meta-analysis reported that patients with early mobilization (within 3 weeks after surgery) postoperative protocols demonstrated improved functional outcomes [51]. Postoperative management, especially the time to allow weightbearing, varied in these studies. Matsui et al. [19] reported that weightbearing and active range of motion exercise were permitted the day after surgery. Patients of Yeo et al. [11], DeVries et al. [22], Yi et al. [23], and Zeng et al. [24] remained non-weightbearing until 2 weeks. Li et al. [20] reported that weightbearing was permitted after 4 weeks. In the study of Rigby et al. [21], they allowed full weight bear after 20 days in the open group, whereas the time in the arthroscopic group was 3 days because of their hypothesis that patients had less swelling and pain. Thus, there is still no consensus on the proper time to allow weightbearing up to date.

There are also several limitations and potential biases to pay attention to. Eight included studies were LOE III, and only one was RCT of LOE I. The follow-up time: (1) varied among these studies; (2) less than 2 years in four studies; (3) within one study, the time length in the arthroscopic group was far less than that of the open group. Besides, intra-articular comorbidity existed in patients and was treated during operative procedures in seven studies. However, the patients with additional pathology in the other two studies were excluded. With 
regard to the data collection, there was no clear statement whether surgeons and investigators were separated to assess the outcomes in the included studies.

\section{Conclusion}

In conclusion, arthroscopic repair for lateral ankle instability shows excellent clinical results comparable to open repair. Patients receiving either procedure result in similar functional and radiographic outcomes with equivalent complication rates. Especially, arthroscopic repair, characterized by minimal invasiveness, might provide better recovery (AOFAS scores) and alleviate more pain (VAS scores). Further RCTs with a larger sample-size and longer follow-up time are still required to achieve a more reliable conclusion.

\section{Supplementary information}

Supplementary information accompanies this paper at https://doi.org/10. 1186/s13018-020-01886-1.

Additional file 1. PRISMA 2009 checklist

\section{Abbreviations}

ATFL: Anterior talofibular ligament; CFL: Calcaneofibular ligament; IER: Inferior extensor retinaculum; RCT: Randomized controlled trial;

MINORS: Methodological index for non-randomized studies; MD: Mean difference; AOFAS: American Orthopaedic Foot \& Ankle Society; VAS: Visual analog scale; SPN: Superficial peroneal nerve; LOE: Level of evidence; AS: Arthroscopic; JSSF: Japanese Society for Surgery of the foot anklehindfoot; NR: Not reported; DVT: Deep venous thrombosis

\section{Acknowledgements}

We would like to express gratitude to John Valerius, a professional English teacher, for taking the time to review our paper.

\section{Authors' contributions}

XZ and SW designed the study. XZ and CK performed database searches. XZ and $C Z$ reviewed the studies. SW and FX resolved disagreements during the review process. ZL generated the synthesis of results. XZ and ZL drafted the manuscript. SW and FX edited the manuscript. All authors read and approved the final manuscript.

\section{Funding}

This study is supported by the Wuhan Cultivation Program for Middle-aged and Young Medical Talents (Grant No. 2014-77).

\section{Availability of data and materials}

The datasets used and/or analyzed during the current study are available from the corresponding author on reasonable request.

\section{Ethics approval and consent to participate}

Not applicable.

\section{Consent for publication}

Not applicable.

\section{Competing interests}

The authors declare that they have no competing interests.

\section{Author details}

'Department of Orthopaedics, General Hospital of Central Theater Command (Wuhan General Hospital of Guangzhou Command, previously), No. 627, Wuluo Road, Wuhan 430030, Hubei Province, PR China. ${ }^{2}$ Center for Stem Cells and Medicine, Department of Cell Biology, Navy Medical University (Second Military Medical University, previously), Shanghai, PR China.
Received: 24 May 2020 Accepted: 12 August 2020

Published online: 26 August 2020

\section{References}

1. Herzog MM, Kerr ZY, Marshall SW, Wikstrom EA. Epidemiology of ankle sprains and chronic ankle instability. J Athl Train. 2019;54(6):603-10.

2. Roos KG, Kerr ZY, Mauntel TC, Djoko A, Dompier TP, Wikstrom EA. The epidemiology of lateral ligament complex ankle sprains in National Collegiate Athletic Association Sports. Am J Sports Med. 2017;45(1):201-9.

3. Glick JM, Gordon RB, Nishimoto D. The prevention and treatment of ankle injuries. Am J Sports Med. 1976;4(4):136-41.

4. Ferran NA, Maffulli N. Epidemiology of sprains of the lateral ankle ligament complex. Foot Ankle Clin. 2006;11(3):659-62

5. Brostrom L. Sprained ankles. V. Treatment and prognosis in recent ligament ruptures. Acta Chir Scand. 1966;132(5):537-50.

6. DiGiovanni BF, Partal G, Baumhauer JF. Acute ankle injury and chronic lateral instability in the athlete. Clin Sports Med. 2004;23(1):1-19 v.

7. Martin RL, Davenport TE, Paulseth S, Wukich DK, Godges JJ. Ankle stability and movement coordination impairments: ankle ligament sprains. J Orthop Sports Phys Ther. 2013:43(9):A1-40

8. Shimozono Y, Hoberman A, Kennedy JG, Takao M. Arthroscopic anterior talofibular ligament repair with use of a 2-portal technique. JBJS Essent Surg Tech. 2019;9(4):e45.1-2.

9. O'Loughlin PF, Murawski CD, Egan C, Kennedy JG. Ankle instability in sports. Phys Sportsmed. 2009;37(2):93-103.

10. Brostrom L. Sprained ankles. VI. Surgical treatment of "chronic" ligament ruptures. Acta Chir Scand. 1966;132(5):551-65.

11. Yeo ED, Lee KT, Sung IH, Lee SG, Lee YK. Comparison of all-inside arthroscopic and open techniques for the modified brostrom procedure for ankle instability. Foot Ankle Int. 2016;37(10):1037-45.

12. Gould N, Seligson D, Gassman J. Early and late repair of lateral ligament of the ankle. Foot Ankle. 1980;1(2):84-9.

13. Hawkins RB. Arthroscopic stapling repair for chronic lateral instability. Clin Podiatr Med Surg. 1987;4(4):875-83

14. Ferkel RD, Fasulo GJ. Arthroscopic treatment of ankle injuries. Orthop Clin North Am. 1994;25(1):17-32.

15. Nery C, Raduan F, Del Buono A, Asaumi ID, Cohen M, Maffulli N. Arthroscopic-assisted Brostrom-Gould for chronic ankle instability: a longterm follow-up. Am J Sports Med. 2011;39(11):2381-8.

16. Kim ES, Lee KT, Park JS, Lee YK. Arthroscopic anterior talofibular ligament repair for chronic ankle instability with a suture anchor technique. Orthopedics. 2011;34(4):273.

17. Baumbach SF, Braunstein M, Herterich V, Bocker W, Waizy H, Polzer H. Arthroscopic repair of chronic lateral ankle instability. Oper Orthop Traumatol. 2019;31(3):201-10.

18. Guelfi M, Zamperetti M, Pantalone A, Usuelli FG, Salini V, Oliva XM. Open and arthroscopic lateral ligament repair for treatment of chronic ankle instability: A systematic review. Foot Ankle Surg. 2018;24(1):11-8.

19. Matsui K, Takao M, Miyamoto W, Matsushita T. Early recovery after arthroscopic repair compared to open repair of the anterior talofibular ligament for lateral instability of the ankle. Arch Orthop Trauma Surg. 2016; 136(1):93-100.

20. Li H, Hua Y, Li H, Ma K, Li S, Chen S. Activity level and function 2 years after anterior talofibular ligament repair: a comparison between arthroscopic repair and open repair procedures. Am J Sports Med. 2017;45(9):2044-51.

21. Rigby RB, Cottom JM. A comparison of the "All-Inside" arthroscopic Brostrom procedure with the traditional open modified Brostrom-Gould technique: A review of 62 patients. Foot Ankle Surg. 2019;25(1):31-6.

22. DeVries JG, Scharer BM, Romdenne TA. Ankle stabilization with arthroscopic versus open with suture tape augmentation techniques. J Foot Ankle Surg. 2019;58(1):57-61.

23. Yi G, Fu S, Yang J, Wang G, Liu Y, Guo X, et al. A comparative study of allarthroscopic technique and modified open Brostrom technique in repair of anterior talofibular ligament with anchors. Zhongguo Xiu Fu Chong Jian Wai Ke Za Zhi. 2019;33(12):1503-9.

24. Zeng G, Hu X, Liu W, Qiu X, Yang T, Li C, et al. Open Brostrom-Gould Repair vs Arthroscopic Anatomical Repair of the Anterior Talofibular Ligament for Chronic Lateral Ankle Instability. Foot Ankle Int. 2020;41(1):44-9.

25. Marx RG, Wilson SM, Swiontkowski MF. Updating the assignment of levels of evidence. J Bone Joint Surg Am. 2015;97(1):1-2. 
26. Slim K, Nini E, Forestier D, Kwiatkowski F, Panis Y, Chipponi J. Methodological index for non-randomized studies (minors): development and validation of a new instrument. ANZ J Surg. 2003;73(9):712-6.

27. Hozo SP, Djulbegovic B, Hozo I. Estimating the mean and variance from the median, range, and the size of a sample. BMC Med Res Methodol. 2005;5:13.

28. Melsen WG, Bootsma MC, Rovers MM, Bonten MJ. The effects of clinical and statistical heterogeneity on the predictive values of results from metaanalyses. Clin Microbiol Infect. 2014;20(2):123-9.

29. Xu C, Li M, Wang C, Liu H. A comparison between arthroscopic and open surgery for treatment outcomes of chronic lateral ankle instability accompanied by osteochondral lesions of the talus. J Orthop Surg Res. 2020;15(1):113

30. Woo BJ, Lai MC, Koo K. Arthroscopic versus open Brostrom-Gould repair for chronic ankle instability. Foot Ankle Int. 2020. https://doi.org/10.1177/ 1071100720914860 .

31. Feng SM, Maffulli N, Oliva F, Wang AG, Sun QQ. Arthroscopic remnant-preserving anterior talofibular ligament reconstruction does not improve mid-term function in chronic ankle instability. Injury. 2020;51(8):1899-904.

32. Brodsky AR, O'Malley MJ, Bohne WH, Deland JA, Kennedy JG. An analysis of outcome measures following the Brostrom-Gould procedure for chronic lateral ankle instability. Foot Ankle Int. 2005;26(10):816-9.

33. Maffulli N, Del Buono A, Maffulli GD, Oliva F, Testa V, Capasso G, et al. Isolated anterior talofibular ligament Brostrom repair for chronic lateral ankle instability: 9-year follow-up. Am J Sports Med. 2013;41(4):858-64

34. Ferkel RD, Scranton PE Jr. Arthroscopy of the ankle and foot. J Bone Joint Surg Am. 1993;75(8):1233-42.

35. Kashuk KB, Landsman AS, Werd MB, Hanft JR, Roberts M. Arthroscopic lateral ankle stabilization. Clin Podiatr Med Surg. 1994;11(3):407-23.

36. Pereira H, Vuurberg G, Gomes N, Oliveira JM, Ripoll PL, Reis RL, et al. Arthroscopic repair of ankle instability with all-soft knotless anchors. Arthrosc Tech. 2016;5(1):e99-e107.

37. Wang J, Hua Y, Chen S, Li H, Zhang J, Li Y. Arthroscopic repair of lateral ankle ligament complex by suture anchor. Arthroscopy. 2014; 30(6):766-73.

38. Brown AJ, Shimozono Y, Hurley ET, Kennedy JG. Arthroscopic versus open repair of lateral ankle ligament for chronic lateral ankle instability: a metaanalysis. Knee Surg Sports Traumatol Arthrosc. 2020;28(5):1611-8.

39. Frost SC, Amendola A. Is stress radiography necessary in the diagnosis of acute or chronic ankle instability? Clin J Sport Med. 1999;9(1):40-5.

40. Jeong BO, Kim TY, Song WJ. Effect of preoperative stress radiographic findings on radiographic and clinical outcomes of the modified brostrom procedure for chronic ankle instability. J Foot Ankle Surg. 2016;55(1):125-8.

41. Lee KT, Park YU, Jegal H, Park JW, Choi JP, Kim JS. New method of diagnosis for chronic ankle instability: comparison of manual anterior drawer test, stress radiography and stress ultrasound. Knee Surg Sports Traumatol Arthrosc. 2014;22(7):1701-7.

42. Hertel J. Functional instability following lateral ankle sprain. Sports Med. 2000;29(5):361-71.

43. Dimmick S, Kennedy D, Daunt N. Evaluation of thickness and appearance of anterior talofibular and calcaneofibular ligaments in normal versus abnorma ankles with MRI. J Med Imaging Radiat Oncol. 2008;52(6):559-63.

44. Brown AJ, Shimozono Y, Hurley ET, Kennedy JG. Arthroscopic repair of lateral ankle ligament for chronic lateral ankle instability: a systematic review. Arthroscopy. 2018:34(8):2497-503.

45. Acevedo Jl, Palmer RC, Mangone PG. Arthroscopic Treatment of Ankle Instability: Brostrom. Foot Ankle Clin. 2018:23(4):555-70

46. Guelfi M, Nunes GA, Malagelada F, Cordier G, Dalmau-Pastor M. Arthroscopic-assisted versus all-arthroscopic ankle stabilization technique. Foot Ankle Int. 2020;1071100720938672.

47. Acevedo Jl, Ortiz C, Golano P, Nery C. ArthroBrostrom lateral ankle stabilization technique: an anatomic study. Am J Sports Med. 2015; 43(10):2564-71.

48. Yasui Y, Murawski CD, Wollstein A, Takao M, Kennedy JG. Operative treatment of lateral ankle instability. JBJS Rev. 2016;4(5):01874474201605000-00006

49. So $\mathrm{E}$, Preston $\mathrm{N}$, Holmes $\mathrm{T}$. Intermediate- to long-term longevity and incidence of revision of the modified Brostrom-Gould procedure for lateral ankle ligament repair: a systematic review. J Foot Ankle Surg. 2017:56(5):1076-80.

50. Lopes R, Andrieu M, Cordier G, Molinier F, Benoist J, Colin F, et al. Arthroscopic treatment of chronic ankle instability: prospective study of outcomes in 286 patients. Orthop Traumatol Surg Res. 2018;104(8s): S199-s205.

51. Vopat ML, Tarakemeh A, Morris B, Hassan M, Garvin P, Zackula R, et al. Early versus delayed mobilization postoperative protocols for lateral ankle ligament repair: a systematic review and meta-analysis. Orthop J Sports Med. 2020;8(6):2325967120925256.

\section{Publisher's Note}

Springer Nature remains neutral with regard to jurisdictional claims in published maps and institutional affiliations.
Ready to submit your research? Choose BMC and benefit from:

- fast, convenient online submission

- thorough peer review by experienced researchers in your field

- rapid publication on acceptance

- support for research data, including large and complex data types

- gold Open Access which fosters wider collaboration and increased citations

- maximum visibility for your research: over $100 \mathrm{M}$ website views per year

At BMC, research is always in progress.

Learn more biomedcentral.com/submissions 